\title{
Cascades of Coverage: Dynamics of Media Attention to Social Movement Organizations
}

\author{
Charles Seguin, University of North Carolina
}

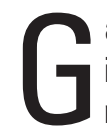
aining attention in the mass media is a key goal of many social movement organizations (SMOs). The dominant explanation of media attention to SMOs is that the media act like a filter, selecting some types of SMOs and events for attention, and ignoring others based on characteristics of these SMOs, events, and their political environment. In contrast to this "bias model," I argue that some media attention to SMOs is characterized by positive feedback, or rich-get-richer processes: past media attention increases the likelihood of future media attention through its effect on the SMO and on other media outlets. Like other positive feedback systems, media attention can be path dependent, is routinely punctuated by large cascades of attention to previously obscure SMOs, and can be contingent on "accidents" of history: at critical junctures, individuals, organizations, and events have the potential to radically impact the extent of media attention to their movements and organizations. Media attention to SMOs can also become decoupled from the types of events that initially sparked their media attention, becoming spokes-organizations for their movements and receiving media attention for events and stories that they themselves are not involved. In support of this theory, I first show that media attention is, similar to other positive feedback processes, power-law distributed across SMOs using two national (US) data sets. I then illustrate the process of positive feedback in media attention through a case study of the Black Panther Party's rise to prominence in media attention.

In democratic countries with independent news media, a key goal of social movement organizations (SMOs) is to gain attention, or visibility, in the mass media. The dominant explanation for media attention to SMOs is that the media pay differential attention to SMOs based on biased interpretations of which events,

The author acknowledges the support of a National Science Foundation Graduate Research Fellowship while this research was being conducted. He thanks his adviser, Kenneth (Andy) Andrews, for his unflagging support of this project. He also thanks Howard Aldrich, Alison Appling, Chris Bail, Shawn Bauldry, Frank Baumgartner, Michael Biggs, Neal Caren, Brandon Gorman, Shane Eliot, Aseem Hasnain, Jonathan Horowitz, Ali Kadivar, Danielle Kane, Charles Kurzman, Francois Nielsen, Jordan Radke, David Rigby, Didem Torkoglu, Tiantian Yang, Haj Yazdiha, the audience at the Empirical Applications of Mathematical Models at the ASA meeting in Denver 2012, members of the Culture and Politics Workshop at the University of North Carolina, and members of the Inequality Workshop at the University of North Carolina for their helpful comments and guidance. This paper would not have been possible without data collected by Edwin Amenta and Neal Caren. Direct correspondence to Charles Seguin, Department of Sociology, CB 3210, University of North Carolina at Chapel Hill 27599-3210, seguin@live.unc.edu. 
messages, and organizations they consider newsworthy. Bias thus acts like a filter, selecting some types of SMOs and events for attention while ignoring others. Understanding this media bias has been central for both methodological and substantive reasons in the study of social movements (e.g., Myers and Caniglia 2004; Oliver and Myers 1999). Movement scholars have shown that the news media pays more attention to larger, more disruptive SMOs with more elite allies, more resonant issue framing, and greater policy influence (e.g., Amenta et al. 2009; Andrews and Caren 2010). The bias model thus suggests that media attention is a distorted reflection of the properties of SMOs and their political environments.

Other movement scholarship suggests that the bias model is incomplete, since media attention has effects on movements and SMOs. Programmatic theoretical work argues that media and movements are "interacting" or "coevolving" systems (Gamson and Wolfsfeld 1993; Koopmans 2004; Oliver and Myers 2003). These scholars argue that while media representations of movements are shaped by media biases, media attention, and its pursuit, also shapes movements. Media attention, for instance, helps SMOs grow their membership, attract elite allies, and influence political and cultural outcomes (e.g., Vliegenthart, Oegema, and Klandermans 2005). Media scholars also note that media attention often occurs in cascades, largely as a result of media outlets imitating one another in chasing "hot" new stories to deliver to audiences in the context of a competitive capitalist system $^{1}$ (Baumgartner and Jones 2009; Boydstun 2013; Walgrave and Vliegenthart 2010). These internal media dynamics have largely been ignored in studies' media attention to SMOs (although see for example Amenta et al. 2012; Gamson 2004).

While the bias model ignores these interactions, they have consequences for understanding how and why some SMOs garner more media attention than others. I argue that some media attention to SMOs is characterized by positive feedback, or rich-get-richer processes. This suggests that, like other positive feedback systems, media attention is path dependent and routinely punctuated by large cascades of attention to previously obscure SMOs. Media attention can therefore be contingent on "accidents" of history: at critical junctures, individuals, organizations, and events have the potential to radically impact the extent of media representation of their movements (Sewell 1996). These dynamics may help explain why, despite the centrality of media attention to SMO efforts, most SMOs receive little to no coverage (Sobieraj 2011). These dynamics may also help explain why, at times, even small organizations explode unpredictably into the media spotlight, garnering orders of magnitude more attention than their peers.

Similar to other path-dependent phenomena, media attention to SMOs can become decoupled from the types of events that sparked the attention in the first place. As they become embedded in a news story, SMOs can become spokesorganizations for their movements and receive media attention for events and stories in which they themselves are not involved (Gamson 2004). This decoupling can make media attention to SMOs disproportional to their resources, activities, and political impacts.

Because accidents of history can have enduring consequences in positive feedback systems, these models offer "strong explanatory power but little predictive power" (Baumgartner and Jones 2009, 307; see also Boydstun 2013). Therefore, I do not attempt to predict which specific SMOs will receive more attention than 
others, but rather to show that positive feedback can explain key facts about the distribution and dynamics of attention to some SMOs. I first show that, like other positive feedback systems (Biggs 2005; van de Rijt et al. 2013; Simon 1955), media attention to SMOs is power-law distributed in two data sets describing counts of television newscasts and newspaper articles mentioning US SMOs. I then describe a case study of the rise in media attention of the Black Panther Party, one of the largest and most dramatic media cascades to an SMO in US history, showing that the Panthers used their early attention to spark a positive feedback process.

\section{Media Bias and Social Movement Organizations}

The dominant model of media and social movements suggests that media acts as a kind of filter that takes information from the world and translates it into news. Journalists, editors, and news organizations act as gatekeepers that select organizations and events from the larger world for news coverage according to their resonance with new values (Earl et al. 2004; Galtung and Ruge 1965). Within this "bias model," media attention to SMOs is a function of the characteristics of SMOs and their political environments, which are (generally implicitly) assumed to be independent of prior media attention (e.g., Andrews and Caren 2010).

Movement scholars have pointed to four primary aspects of SMOs and their political environments that affect media attention: the scope of conflict, resources, frames, and tactics. The "scope of conflict" refers to the extent to which other political actors, including elite allies and opponents, the state, counter-movements, and crowds, have been drawn into the movement's fight (Gamson and Wolfsfeld 1993). These other actors, particularly the state and other elites, draw routine media attention, and SMOs who draw them into the fight are likely to receive more media attention. The media prefer to cover large, important actors, and thus SMOs with more resources tend to receive more attention. SMOs are more likely to receive media attention when they frame their messages in ways that resonate with the attention cycle, or issues currently prominent in the news media (Andrews and Caren 2010; McCarthy, McPhail, and Smith 1996). Disruptive tactics, such as protests that draw arrests, resonate with news values and have been a common path to media attention (e.g., Gitlin 1980), although disruption falls far short of a sufficient condition for media attention (Sobieraj 2011).

\section{Media and SMOs as Interacting Systems}

The bias model continues to motivate empirical work, but it is limited. Social movement theory has stressed that the media and movements interact in key ways. Media bias works to shape reporting of movements, but media attention also affects movements and SMOs. This means that media attention to SMOs is part of a dynamic process in which media representations are both causes and consequences of SMO characteristics. Moreover, dynamic processes-primarily capitalist and professional competition for audiences-occur across news outlets and between journalists, which shapes media attention over time. 
On a national level, actors not already central to a political conflict are likely to get their information about an SMO through the news media. Media attention to SMOs is therefore largely necessary to draw them into the SMO's fight, expand the scope of conflict, mobilize SMO constituencies, draw crowds, and attract counter-movements (Gamson 2004; Koopmans 2004; Meyer and Staggenborg 1996, 1642; Oliver and Myers 1999). Perhaps most importantly, movement scholars have argued that media attention may be necessary for movements to influence state agendas (Koopmans 2004).

Media attention also tends to increase an SMO's resources by serving as "free advertising" - helping SMOs reach constituents, sympathizers, and broader publics (McCarthy and Zald 1977; Vliegenthart, Oegema, and Klandermans 2005). Thus, even as other resources and actors draw media attention to an SMO, media attention tends also to bring new actors into the SMO fight—whether as allies or opponents—and thus to attract still more media attention.

Movements and SMOs tend to base their tactics in part on what has attracted media attention in the past (Sobieraj 2011). Koopmans and Olzak (2004), for instance, show that, in an extreme right-wing German movement, a tactic of attacking asylum seekers was initially resonant in the media, leading the movement to emphasize this tactic above others and to the movement becoming framed as primarily anti-asylum seekers. Bail (2012) shows that, as organizations employing "Muslims as enemies" frames gained success in the media, they drew similar organizations into employing the frame while increasing their centrality to the larger organizational field. Adaptation to media attention need not necessarily be the result of conscious and strategic decisions by organizations. Rather, media attention to certain tactics and frames is likely to attract new recruits with preference for those same frames and tactics (Gitlin 1980; Koopmans and Olzak 2004). Media attention is thus an occasion for SMOs to discover, and accentuate, resonant tactics and frames, which in turn are likely to attract more attention.

\section{Media Attention Cascades}

In capitalist systems, journalists and news outlets are in competition for both audiences and advertisers. The American context is unique even among Western countries in its low level of public subsidy for news media (Brüggemann et al. 2014). Capitalism shapes news content in many ways; critically for the argument here, competition among news outlets means that news outlets are afraid of not carrying "hot" stories that other outlets are carrying for fear of losing readers or viewers (Boydstun 2013). Thus, when a story or issue is highly covered in one news outlet, it is very likely to be highly covered in other outlets (Atkinson, Lovett, and Baumgartner 2014; Gorman and Seguin Forthcoming, 7-8; Hilgartner and Bosk 1988). While different news outlets generally pay attention to the same things, they often frame things according to ideological differences (Snow, Vliegenthart, and Corrigall-Brown 2007). Thus, news outlets respond to one another's news with counter-framings that contest their ideological opponents' understanding of issues. A positive or negative article about an SMO in one media outlet may therefore elicit increased attention in other ideologically dissimilar outlets as they attempt to counter-frame the SMO. 
Journalists also deliberately structure media attention to an issue or actor into "stories" or connected narratives-past news stories are causal in guiding selection criteria for future stories, with an eye toward thematic continuity. Thus, once an event or entity becomes defined as news, it will continue to be defined as news even if much of what made it of initial interest is gone (Fishman 1978; Galtung and Ruge 1965; Koopmans and Vliegenthart 2011). These sorts of dynamics can underlie moral panics, such as the construction of "crime waves" as one type of crime becomes a news story, and these events are then disproportionately reported (Fishman 1978; Hall 1978, 71-72). As a result of these dynamics, media attention is rarely proportionate to events in the world, but rather switches between dramatic under-attention and over-attention (Baumgartner and Jones 2009; Boydstun 2013).

SMOs that receive a fair amount of media attention are likewise embedded in stories (Amenta et al. 2012). These SMOs enjoy what Gamson and Wolfsfeld call "standing"- defined as the extent to which journalists take a movement actor seriously (1993). Standing is not an objective quantity that is simply observed by journalists. Rather, since journalists operate in an uncertain environment, they often look to what other journalists have already covered to determine, and construct, the standing of a movement actor (Gamson 2004). When SMOs enjoy standing, they can be covered as spokes-organizations for movements-receiving attention for actions they did not initiate (Amenta et al. 2012; Gamson 2004). Thus, as SMOs become institutionalized as spokes-organizations, their media attention becomes increasingly decoupled from the kinds of dramatic events that may have originally gotten them into the spotlight.

\section{Positive Feedback}

The relationships identified above form a positive feedback process: media attention tends to increase the same variables that increase media attention, whether they be the scope of conflict, organization resources, frames, tactics, or the extent to which an SMO is embedded in an ongoing news story. Through these mechanisms, past media attention exerts a positive causal effect on present and future media coverage. Figure 1 illustrates the argument. It should be noted that these mechanisms are probabilistic: past media attention only makes future media attention, a generally rare event, more likely than it would have otherwise been. These virtuous cycles therefore do not go on forever, but eventually die outindeed, most news cascades end quickly.

Contingent historical events have enduring impacts in positive feedback processes, making the identification of positive feedback difficult since the impact of "errors," or small events, does not wash out with increasing observations (Arthur, Ermoliev, and Kaniovski 1987). Bi-directional causal relationships between the dependent and "independent" variables are also endemic to positive feedback processes. Scholars thus do not recommend regression methodologies for the study of positive feedback processes (see, e.g., Baumgartner and Jones 2009, 307-10; Biggs 2005, 1687); meaning that we must consider novel methods to analyze positive feedback. Both empirical and theoretical work shows that inequality generated by positive feedback takes the form of a power-law 
Figure 1. Positive feedback in media attention to SMOs

Bias Model:

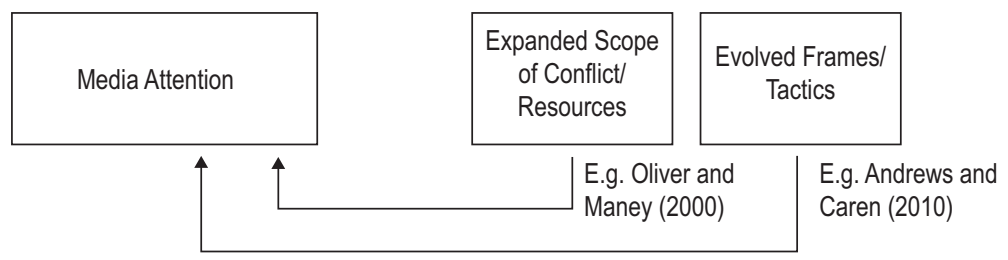

Positive Feedback:

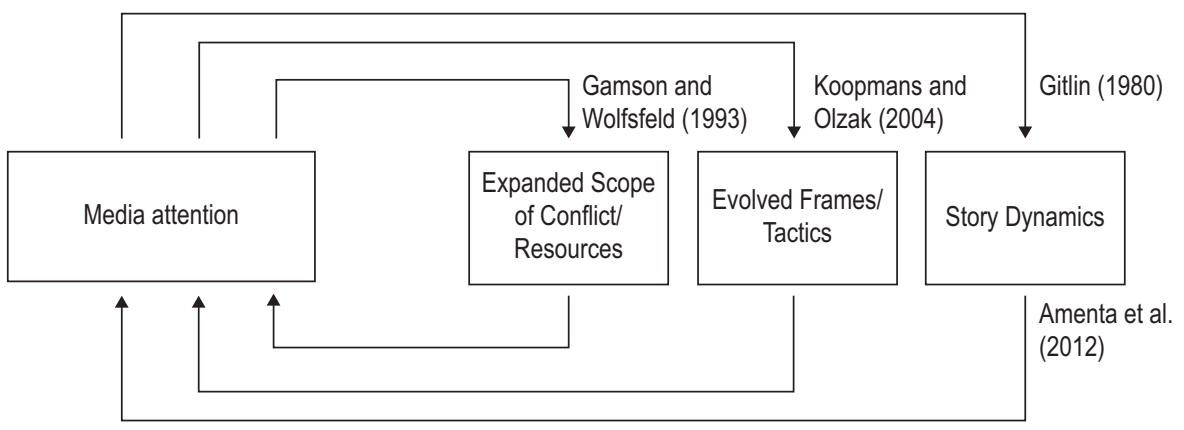

distribution, a type of highly skewed distribution ${ }^{2}$ (e.g., Biggs 2005; Newman 2005; Simon 1955; van de Rijt et al. 2013). Following the lead of these scholars, I evaluate the positive feedback model by testing the implication that the sizes of cascades of attention to SMOs are power-law distributed. I then discuss the Black Panthers case study.

\section{Distributional Analysis}

I test for power-law distributions in two data sets. The first data set contains counts of 298,359 New York Times articles mentioning 1,247 unique US SMOs over the entire twentieth century gathered by an electronic search by Amenta et al. (2009). The second data set contains counts of SMO mentions from the abstracts of the Vanderbilt Television News Archives. The abstracts are descriptions of evening news stories that aired on the major television networks (NBC, ABC, CBS) from fall 1968 to 2009. This data set was generated by an electronic search for the SMO names used in Amenta et al (2009) and contains 15,858 stories mentioning 395 distinct SMOs. SMOs were selected for inclusion in these data sets according to definitions of SMOs given by McCarthy and Zald (1977) and Gamson (1975), which conceptualize SMOs as formal organizations tied to the goals of social movements, or seeking to mobilize new constituencies against targets within government. These data include only SMOs with national political goals (for more detail, see Amenta et al. 2009, 639-40). Local SMOs and media are outside the scope of the theory, because local SMOs have more face-to-face 
relationships with constituents, and because of the more limited competition between local media outlets.

In both data sets, I measure counts of articles or newscasts mentioning specific organizations. While counts are only a rough measure of media attention, they tend to be highly correlated with more sophisticated measures of attention. The correlation between counts of front-page and other articles for the 30 most covered SMOs in the New York Times is 97 (Amenta et al. 2009). Andrews and Caren find that using a more sophisticated measure of attention, including length of articles, placement, and the presence or absence of photos, does not change their results; the correlation between this measure and the raw counts is .95 (2010).

I take the size of cascades of media coverage, or continuous periods of high media attention, to SMOs as the unit of analysis. Some analysts, following practices in the epidemiology literature, separate cascades from one another by periods where there are no events of interest (Biggs 2005, 1696). This strategy is not appropriate for media attention to SMOs, as they often have periods of low coverage between clearly distinct cascades. Further, even relatively rapid rises in media attention, such as those to the Black Panthers and the Students for a Democratic Society, unfold over a period of years-short periods of inattention do not necessarily indicate a substantive break in the cascade. For these reasons, as well as a substantive interest in larger cascades, I define cascades as consecutive periods of high attention to an SMO. For the New York Times, I operationalized the duration of cascades of coverage to SMOs as consecutive years where a group received at least fifty articles. Reflecting the much smaller news hole for movements in television news, I set the cutoff at five stories. This method identified 441 cascades in the New York Times and 153 in the television data. Figure 2 illustrates this cascade measurement strategy on some key SMOs in the New York Times. The SMOs in figure 2 were chosen to give readers a sense of the scale and dynamics of media cascades on some familiar SMOs. I then counted the number of stories or articles in each cascade, and analyzed the size distribution of these cascades. Any cutoff is necessarily somewhat arbitrary; those that are too large will miss smaller cascades, while those that are too small will aggregate distinct cascades. I therefore conducted extensive robustness checks with a wide range of cutoffs (including zero); the results are remarkably robust to alternative specifications. Comparing the two data sets where they overlap in time (1968-2009) shows substantial similarity. The correlation coefficient between organization-year newscasts and Times articles is .6. Only one organization receives more than ten newscasts without also having a cascade in the Times data. Thus, high attention in television only very rarely occurs without substantial attention in the Times as well-likely owing to the larger news hole for print media.

\section{Power-Law Analysis}

The distribution of media coverage to SMOs is highly skewed in both the New York Times and the television news data sets-most SMOs receive very 
Figure 2. Cascades measurement strategy

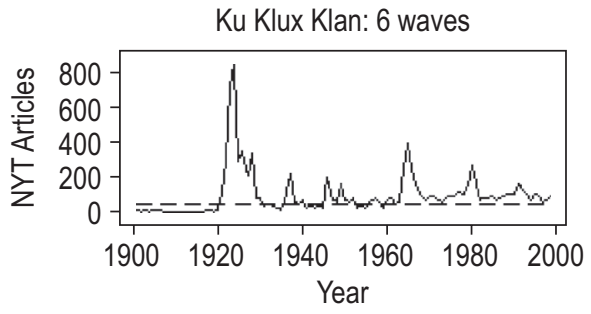

Students for a Democratic Society: 1 wave

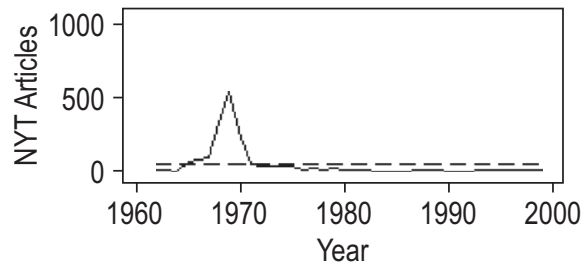

League of Women Voters: 4 waves

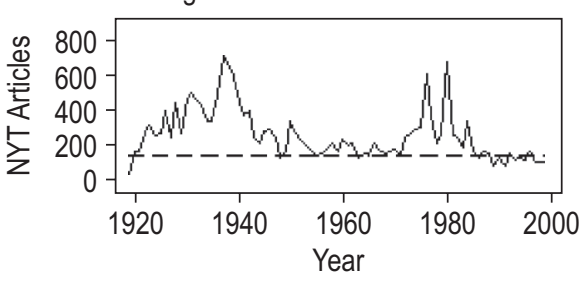

Black Panthers: 1 wave

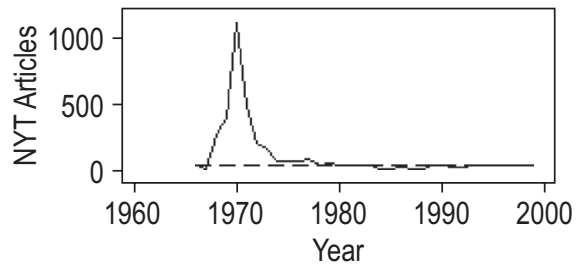

Count

- - Cutoff

Note: The figure illustrates the measurement of news cascades. Cascades occur in years above the article count cutoff. The size of cascades is the total number of articles in all consecutive years above the cutoff. There are 411 cascades identified in the New York Times data. These cases were chosen to show how the cascades measurement works in a variety of conditions, as well as to provide context for the Black Panthers' media cascade with the media attention of some well-known SMOs.

little attention, while a few receive most of their movement's attention. The Gini coefficient measure for inequality in story counts across SMOs is .88 in the Times and .82 in the television data. For comparison, the Gini coefficient for the US wealth distribution in 2008 was .80 (Davies et al. 2009). This dramatic skew means that 86 and 82 percent of organizations in the data are below the mean count of stories in the New York Times and television data, respectively-that is, over 80 percent are "below average" in media representation.

A power-law distribution is one type of skewed distribution, in which the probability density function (pdf) is defined as follows:

$$
f(x)=a x^{-\alpha} \text {. }
$$

It is rare to find power-laws across the entire range of the data; generally, power-laws are found only in the right tail (although in many cases the "tail" encompasses most of the distribution) (Newman 2005). I estimated power-laws for the right tails of the distributions of media coverage in the two data sets via maximum likelihood (Clauset, Shalizi, and Newman 2009). Figures 3 and 4 below show the power-law fit to the right tails of the observed data on log-log plots. ${ }^{3}$ These plots show a good fit to the right tails for the New York Times and the television news data. 
Figure 3. Power-law distribution fit of media attention in the New York Times (1900-2000)

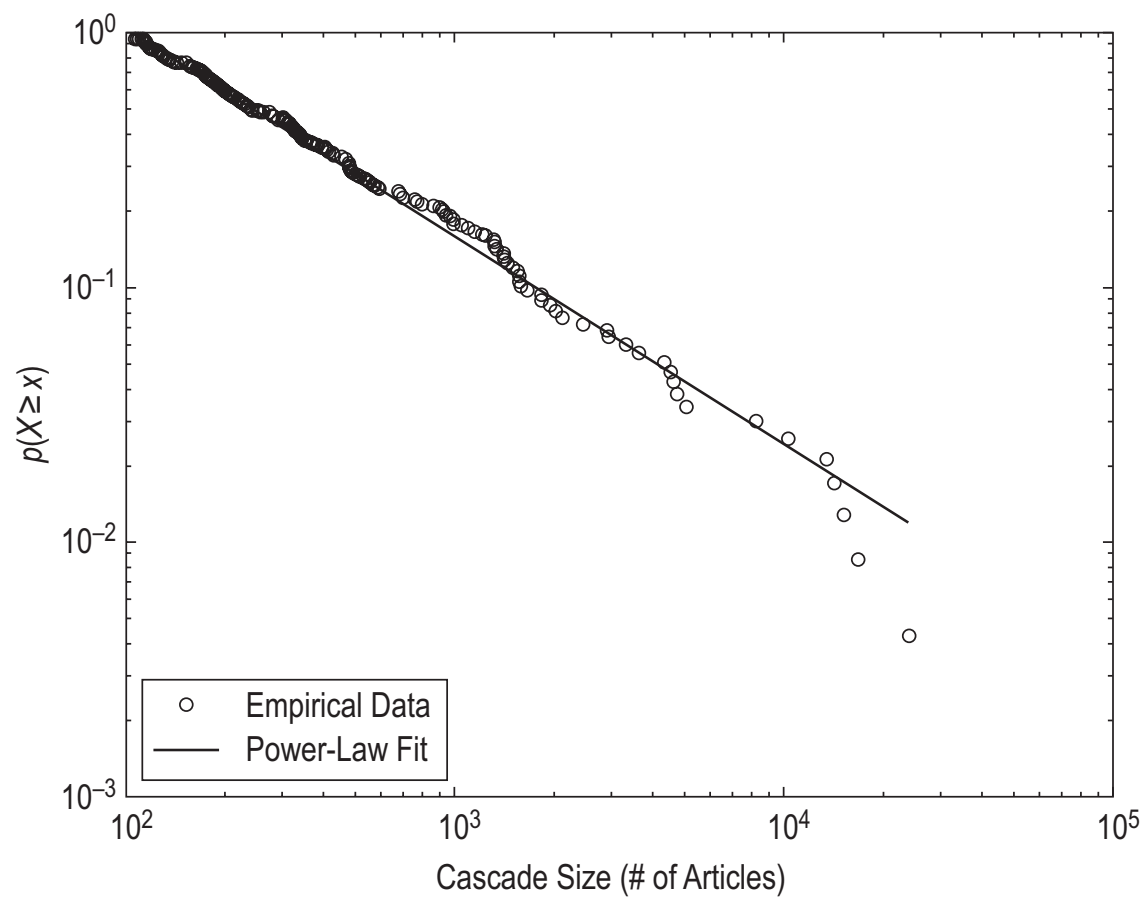

Note: The figure illustrates the size distribution of news cascades; that is, the total number of news articles mentioning an SMO during a period of high media attention, and the power-law fit to that distribution. $N=411$ news cascades to 151 unique organizations.

Even when the power-law is a statistically good fit to some data, the log-normal distribution is often a significantly better fit (Clauset, Shalizi, and Newman 2009). I used a Kolmogorov-Smirnov test for the fit of the power-law to the data, and a log-likelihood ratio test to compare the power-law fit to that of the best-fitting log-normal distribution (Clauset, Shalizi, and Newman 2009). Table 1 displays $p$-values of the null hypothesis for the Kolmogorov-Smirnov tests of a power-law distribution, estimates for the scaling parameter $(\alpha)$ for the best-fit power-law, and $p$-values of likelihood ratio tests against the log-normal distribution. The estimates show that in both cases the Kolmogorov-Smirnov test fails to reject the null hypothesis of power-law. The table also shows that likelihood ratio tests do not reject the power-law in favor of the log-normal. Taken together, these results suggest that power-law distributions are good fits to these data.

Power-law distributions suggest positive feedback; however, they say little about how such a process might work (see, e.g., Newman 1996). Like all quantitative results, power-laws must be interpreted in light of both theory and qualitative understandings of the phenomena. In principle, the power-law distribution in media attention shown here could reflect some positive feedback process that occurs independently from the media. Below, I illustrate the positive feedback process in the cascade of attention to the Black Panthers. 
Figure 4. Power-law distribution fit of media attention in television news (1969-2009)

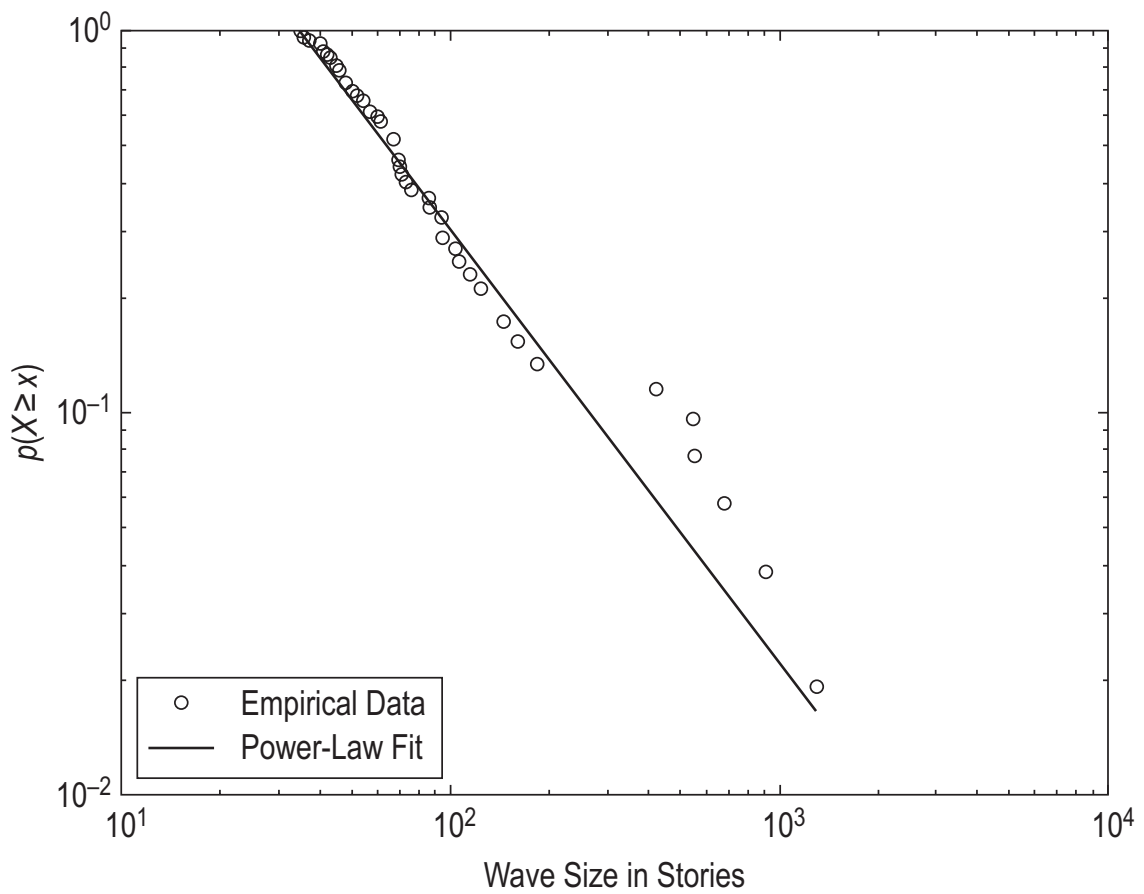

Note: The figure illustrates the size distribution of news cascades; that is, the total number of news broadcasts mentioning an SMO during a period of high media attention, and the powerlaw fit to that distribution. $N=153$ news cascades to 65 unique organizations.

Table 1. Power-Law Test and Fit Statistics

\begin{tabular}{lcccc}
\hline Data & P reject power-law & P reject for log-normal & Alpha & Range \\
\hline New York Times & 0.256 & 0.553 & 1.81 & $104-60,277$ \\
\hline Television & 0.535 & 0.731 & 2.12 & $35-1,291$ \\
\hline
\end{tabular}

\section{The Black Panthers' Avalanche of Attention}

\section{The Black Panthers News Cascade}

Black power emerged as a broad social movement beginning in 1966 and extended through the 1970s. Early calls for black power emerged in the southern civil rights struggle (Jeffries 2009; Tyson 1999), but the movement quickly spread and took strongest root in major cities outside the South. Recent years have seen a surge of historical interest in the Black Power movement. Among the key puzzles of the period is that the Black Power movement included innumerable organizations and leaders (Gerlach and Hine 1970; Joseph 2010), yet the Black Panther Party came to nearly entirely dominate the media attention to the movement, becoming the "privileged signifier of Black militancy" (Singh 1998, 61). This pattern, of a small group exploding from obscurity to dominate the attention 
of their movement, makes the Panthers an ideal case for studying positive feedback. Figure 5 below shows the news cascade to the Black Panthers in three major national newspapers: the Chicago Tribune, Los Angeles Times, and New York Times. ${ }^{4}$ The Panthers national news cascade, as figure 5 demonstrates, began in 1967 and was largely finished by 1974, although they continued to receive low levels of coverage for many years, even up to the present day (Rhodes 2007).

To analyze the Panthers cascade, I used activist memoirs, secondary historical accounts, the population of New York Times articles mentioning the Black Panthers from 1967 to 1969 (965 articles), and other newspaper sources from the period to construct an event catalogue. I briefly compare the Panthers' media attention to that of other Black Power organizations of the time, and then move to a within-case comparison of the Panthers over time.

Table 2 shows the total articles that the New York Times ran mentioning the most prominent Black Power groups from 1967 to 1977. The table demonstrates that the Panthers dominated attention to Black Power organizations over the period. Even the fairly high amount of attention to the Student Non-Violent Coordinating Committee (SNCC) is concentrated in 1967, before the Panthers began receiving high levels of attention. There is no obvious exogenous difference between these groups that accounts for their radically divergent levels of attention, as we would expect from a bias model. Although the Panthers did eventually come to have more resources than these groups, as I discuss later on, the Panthers resources were both a cause and an effect of their media attention, making resources an inadequate explanation. The Panthers' dramatic armed self-defense tactics are another possible explanation. However, other groups had similarly

Figure 5. Black Panthers' cascade of media attention, 1967-1978
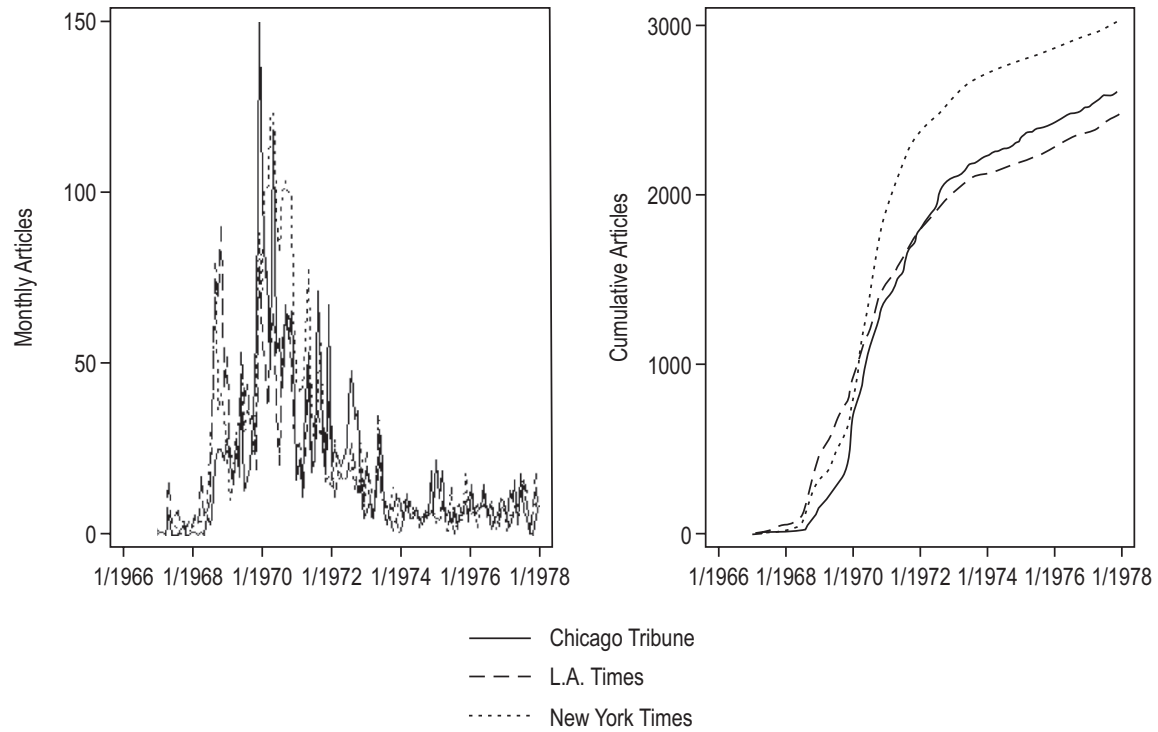

Note: The figure above gives monthly counts of articles mentioning the Black Panthers in three national papers, the Chicago Tribune, Los Angeles Times, and New York Times. 
Table 2. Media Attention to Black Power Organizations (1967-1977)

\begin{tabular}{lc}
\hline Black Power organizations & $\begin{array}{c}\text { Total NYT articles } \\
(\mathbf{1 9 6 7 - 1 9 7 7 )}\end{array}$ \\
\hline Black Panthers & 3019 \\
\hline Republic of New Afrika & 61 \\
\hline Revolutionary Action Movement & 47 \\
\hline SNCC & 445 \\
\hline US Organization & 44 \\
\hline
\end{tabular}

newsworthy tactics. Tactics of the Republic of New Africa included "robberies, shootouts with police, plots to bomb state and federal buildings, and even a plane hijacking" (Davenport 2005, 127). J. Edgar Hoover was quoted in the New York Times testifying before Congress that the Revolutionary Action Movement (RAM) was "dedicated to the overthrow of the capitalist system in the United States, by violence if necessary." Other Times articles detailed mass arrests of RAM members, with confiscations of weapons such as machine guns, and argued that RAM was building an "Army for Ghettoes." I include more detail on RAM in an online appendix (see the supplementary material online) to this article. Members of the US organization were responsible for shootings of Panther leaders. While there were differences between these groups and the Panthers, these differences are insufficient to explain the roughly 50 to 70 times the amount of media attention the Panthers received.

\section{Early History}

Huey Newton and Bobby Seale founded the Black Panther Party for Self Defense $(\mathrm{BPP})^{5}$ in Oakland, California, in October 1966. Inspired by the Black Panther Party of Lowndes County, Alabama, part of a drive to register Black voters by the Student Non-Violent Coordinating Committee, the Oakland Panthers borrowed the Panthers name and much of their iconography. The Oakland Panthers were nevertheless a wholly different and independent organization. Newton took the title of Minister of Defense, while Seale took the title of Party Chairman. Because the Panthers were at war with the white power structure, the Minister of Defense was the highest-ranking position (Seale 1991, 59-69). Seale and Newton originally belonged to a front group for the Revolutionary Action Movement (RAM). Seale was a full-fledged RAM member, but Newton had been denied full membership for being "too bourgeois" (Ogbar 2004, 84; Seale 1991). Before founding the BPP, Newton and Seale had attempted to convince RAM to start armed neighborhood patrols to monitor the police and attract the press. RAM members considered the move "suicidal" (Austin 2006, 32-33). Following this rebuff, Newton and Seale organized the BPP around their ten-point program, heavily influenced by RAM ideology (Ogbar 2004, 81); the program stressed the need for black political autonomy as well as the necessity of ending police brutality (Seale 1991, 66-68).

The Panthers' organization structure was a nested hierarchy, which was later replicated in state and local branches. The Minister of Defense and the Chairman 
were on top, after which the hierarchy branched out to Field Marshall, Minister of Culture, and Communications Secretary. Beneath the Minister of Culture were Lieutenants, Captains, and Officers of the Day, with the Rank-and-File forming the bottom of the pyramid (Austin 2006, 37-39). Recruitment took place through BPP offices, and members began at the Rank-and-File.

\section{Tactics}

Early Panther activities focused on armed neighborhood patrols of Oakland, which they adapted from similar, although unarmed, patrols in the Watts neighborhood of LA (Austin 2006; Bloom and Martin 2013, 39). Panthers sought to demonstrate that Blacks could obtain protection from corrupt police by organizing (Newton and Blake 2009, 127-35). Armed Panthers would follow police patrol cars, observe any stops or arrests made, and inform those arrested of their rights. If someone was arrested on the Panthers' watch, they would try to raise money for bail (Austin 2006, 53-56). These tactics led to highly charged, armed, standoffs between Panthers and police, but did not generate national media attention.

A new tactic brought the Panthers their first national media attention. On May 2, 1967, thirty Black Panthers, most of them openly carrying arms, gathered in Sacramento at the California State Legislature in protest of a proposed gun-control bill that would restrict openly carrying weapons. During the protest, the Panthers were forced out of the building by capital guards in full view of a surprised press corps (Wendt 2007, 172-73). The story figured prominently in the Bay Area press, as well as the national elite media (Bloom and Martin 2013, 61; Rhodes $2007,70)$. The ultimate importance of this tactical innovation, however, was in initiating a positive feedback process, through which the Panthers eventually rose to become a national organization and a national media phenomenon, as I discuss below.

\section{Resources}

While the Sacramento protest was widely covered in the national media, its ultimate importance was in setting into motion a positive feedback process that only much later brought the Panthers to the center of national media attention. After the Sacramento protest, the Panthers were swamped with requests from all over the Bay Area and the rest of the country from activists interested in establishing their own Panther chapters (Austin 2006, 78; Bloom and Martin 2013, 61-62; Rhodes 2007, 70-80). Images of Sacramento would follow the Panthers everywhere-when the Panthers began to set up a chapter in Harlem, for instance, media images of Sacramento had already swayed some potential members (Bloom and Martin 2013, 152). Newton would later write:

Sacramento was certainly a success ... in attracting national attention; even those who did not hear the complete message saw the arms, and this conveyed enough to Black people. The Bay Area became more aware of the Party, and soon we had more members than we could handle. From all across the country calls came to us about establishing chapters and 
branches; we could hardly keep track of the requests. In a matter of months we went from a small Bay Area group to a national organization. (Newton and Blake 2009 [1973], 159)

If the publicity from the Sacramento protest had attracted resources to the Panthers, in the form of greater local support and the founding of chapters nationwide, these same resources later increased the Panthers' media profile. As the rise in attention shown in figure 5 demonstrates, the Panthers were a national media phenomenon; attention rose and fell with similar timing and magnitude in all three papers. Yet, the similarities in the rise and fall of the Panthers' profile in these outlets mask the heterogeneity in the coverage itself, which was influenced heavily by local Panthers' events and chapters-consistent with a large body of scholarship showing that media outlets tend to cover closer events with higher probability than those farther away (e.g., Davenport 2010). The Los Angeles Times covered local college protests, such as those at San Francisco State, which the Panthers were involved in. The assassination of the Chicago Panthers leader, Fred Hampton, in December 1969 can be seen in figure 5 in the massive spike in attention in the Chicago Tribune. The New York Times coverage emphasized local police-Panther conflicts. The Panthers were thus a national media phenomenon partly because they had become a national organization. To summarize: early, limited, attention in the national media helped recruit and strengthen local Panthers chapters, while these local groups later contributed to creating nationwide news attention. Contrary to the bias model, resources were just as much a consequence as a cause of attention.

\section{Story Dynamics}

The Sacramento protest also drew the Panthers into an ongoing story, introducing audiences to the organization and its leadership. Following Sacramento, the New York Times ran two lengthy articles on the personalities and biographies of Panthers leaders. The first article, "A Gun Is Power, Black Panther Says," discussed Newton's biography, and painted Newton as the violent personality at the head of an armed revolutionary organization. These, and similar articles, set the Panthers up as a threat to white society, setting the stage for alarmist coverage of the Panthers, as in a moral panic (Rhodes 2007, 71-82).

The second article since Sacramento, "Call of the Panthers," was a lengthy feature written in the Times Sunday magazine on August 6 by New Left writer Sol Stern. This article discussed the Panthers' organization, ideology, and history over six pages. The article gave the Panthers their preferred framing, painting the Panthers as the spokes-organization for Black urban discontent. The article went into depth on the personalities of Newton and Seale and featured photographs, including a large photo of Huey Newton that had originally appeared in the Panthers' own media (Bloom and Martin 2013, 80), seated in a chair with a rifle in one hand and a spear in the other. The iconic photo of Newton would go on to appear in other papers, such as the Los Angeles Times. The article introduced Newton as willing to commit "revolutionary suicide": to kill police in self-defense and to die if necessary when the time came. While the article was generally 
supportive of the Panthers, the article also characterized them as "pitifully small in numbers," with "meager" organizational resources, and lacking widespread support in the Black community. The article closed thus: "The fate of the Panthers as an organization is not the issue. What matters is that there are a thousand black people in the ghetto thinking privately what any Panther says out loud." These early articles on Newton and his personality were significant in establishing Newton as a media personality and setting the stage for a media frenzy at his later trial (Rhodes 2007, 83-84).

Following Sacramento, the Panthers were continuing to experience considerable repression, and on October 29 the New York Times ran a short article entitled "Patrolman Killed in Coast Gunfight," which detailed a shootout in which Huey Newton and an Oakland police officer were injured, and another, Officer John Frey, ${ }^{6}$ was killed. While the Frey shooting was given only four paragraphs of newsprint in the New York Times, and the Panthers would not be mentioned in the Times for another four months, Newton's subsequent murder trial marks the beginning of sustained high levels of attention to the Panthers.

Over time the Panthers became more established news commodities: the media began to cover less dramatic Panthers' events, as well as give the Panthers attention for events that they did not initiate-similar to other highly covered SMOs (Amenta et al. 2012). The Panthers were mentioned in 488 different New York Times articles in 1969. The content of these articles demonstrate the Panthers' new status as a media institution. Many articles covered trivial events or subjects: an article in September about a march put on by over 150 different organizations spends considerable newsprint on the estimated thirty-five Panthers present; an April article reports an airport car theft, in which one of the theives allegedly had a Panthers membership card-the story was more about the membership card than the car theft; in January, an article discussed the police stopping Panthers leader Kathleen Cleaver on a bridge to ask her some questions. ${ }^{7}$ Other articles linked the Panthers to events they did not cause-such as urban riots or racial tension among soldiers in Vietnam-in effect making the Panthers the organizational voice of the larger Black Power movement, as well as a symptom or leading edge of a generalized racial threat. Thus, the media began searching for "Panthers stories" wherever they could find them. Contrary to the bias model, increasing was not driven solely by exogenous changes in the Panthers organization, events, and political environment, but also by the Panthers becoming instutionalized as an ongoing news story.

To make a more formal test of the hypothesis that the Panthers were receiving greater attention for fewer events, I coupled the total yearly articles in the New York Times to the Panthers with the Collective Action Dataset (see, e.g., Earl, Soule, and McCarthy 2003). The Collective Action Dataset contains stories, coded from an exhaustive search of the New York Times, that mention any collective action event. The data set also contains information about when a social movement organization participated in that collective action. From the Collective Action Dataset I took the yearly number of events that the Panthers were coded as having taken part in, and compared this to the yearly number of New York Times articles that mentioned the Panthers for any reason. Figure 6 below displays both these quantities over time. Events track closely with media coverage at 
Figure 6. New York Times articles mentioning Panthers versus articles mentioning Panthers' collective action events

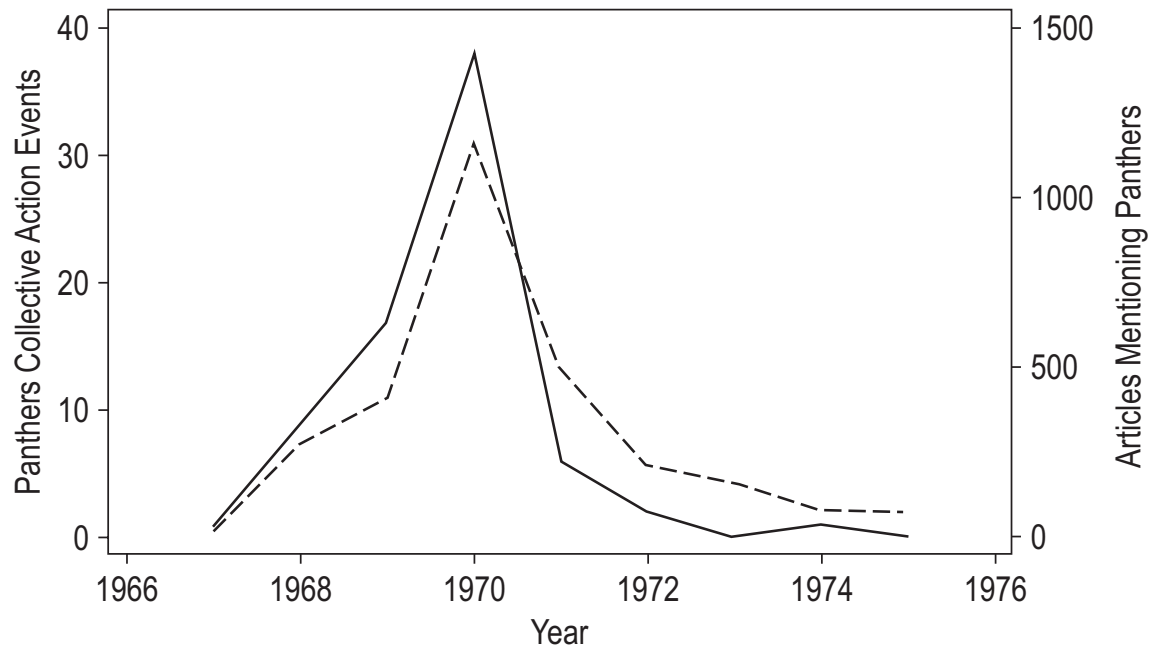

- Panthers Collective Action Events
- - Articles Mentioning Panthers

Note: The figure above shows the number of discrete events in the Collective Action Dataset that are associated with the Black Panthers, and the number of news articles in the New York Times that mention the Black Panthers. $N=3019$ stories and 79 events.

around a 1/25 ratio until 1970-1971, when event counts begin to decline more rapidly than do article counts. Figure 7 below shows the total number of New York Times articles about collective action events the Panthers took part in, divided by the total number of New York Times articles mentioning the Panthers. The figure shows that the percentage of articles referencing an event, which was never large, declines steadily throughout this period as the Panthers became their own national story. The time trend is statistically signifcant $(p<.01)$. While it is hard, perhaps even impossible (Davenport 2010), to know what percentage of the events that Panthers participated in received media attention, figure 7 demonstrates that those stories that were written about collective action events constituted a diminishing share of media attention to the Panthers. Thus, as the Panthers became embedded into an ongoing narrative, dramatic events became less necessary to attract media attention. This point is exemplified by continuing media attention, even up to the present, long after their organization dissolved (Rhodes 2007).

\section{Scope of Conflict}

Media attention to the Panthers not only drew new recruits and donors to the organization. It also drew other actors into the fight, both as allies and as enemies of the Panthers. These included celebrities and other elites. These same actors then engaged with the media to bring about more news. Central to the expansion of the scope of conflict, and attendent media attention, was the role of state 
Figure 7. Share of New York Times articles mentioning Black Panthers that feature Panthers' collective action events

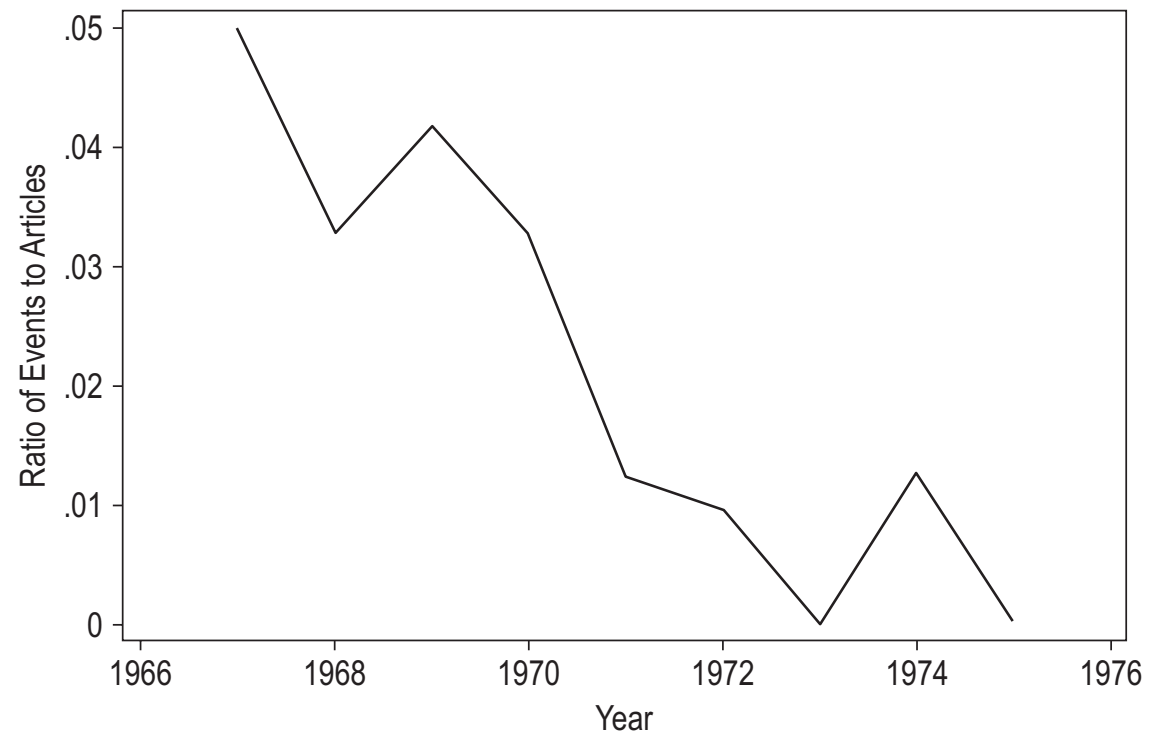

Note: The figure above shows the ratio of the number of discrete events in the Collective Action Dataset that are associated with the Black Panthers to the number of news articles in the New York Times that mention the Black Panthers. The ratio expresses the proportion of New York Times articles on the Black Panthers that were about a collective action event. The declining ratio over time suggests that the Panthers increasingly received media attention in the absence of large collective action events. $N=3019$ stories and 79 events.

actors. In the New York Times, for instance, much attention is devoted to the formation and actions of a police organization, called the "Law Enforcement Group," that was responsible for an attack by off-duty officers on Black Panthers outside a courtroom that left multiple Panthers injured, including one with a fractured skull (Bloom and Martin 2013, 158). The Los Angeles Times devoted considerable space to disputes between Panthers leader Eldridge Cleaver, who was doing a series of lectures at a Berkeley course on racial justice, and thengovernor Ronald Reagan, who opposed the course. While I cannot treat all of these events here, I analyze one of the manifestly most important events-the assassination of the leader of the Chicago BPP branch, Fred Hampton, on the orders of Illinois State Attorney Edward Hanrahan. While it is generally difficult, or perhaps even impossible, to establish whether police or Panthers initiated shootouts (Davenport 2010), the historical evidence is fairly clear that the Hampton killing was initiated by the police.

The assassination took place at 4 a.m. on December 4, 1969, as Hampton and other Panthers slept in his apartment. Heavy shooting occurred, and accounts of the event were immediately disputed by the Panthers and the Chicago police. The next day, the Chicago press and the New York Times ran articles describing the shooting, giving preference to the version offered by Chicago police wherein a drawn-out gun battle took place, in which Panthers 
fired first (Arlen 1973, 20). Panthers responded by giving tours of the apartment where Hampton was killed and, as the local press saw the evidence for themselves, it became clear to them that nearly all the firing had been done by the police (Arlen 1973, 21-22; Bloom and Martin 2013, 238; Rhodes 2007, 279). The next day, following local press coverage in Chicago, the New York Times ran a lengthy article suggesting foul play, followed with a long article detailing an autopsy report that suggested Hampton was killed in his sleep. The Times ran three articles during the following days, echoing calls for inquiries into the slaying. In light of this sympathetic coverage, Panthers chose to follow a media strategy, rather than violent retaliation, to exploit public sympathy for the Hampton killing (Haas 2010, 102). In response, the district attorney, Edward Hanrahan, pursued his own press strategy, releasing police photos of Hampton's apartment with his own descriptions of the evidence printed below the photographs, giving an exclusive interview with the sympathetic Chicago Tribune, and even staging a television reenactment of the shooting with the police who had been involved (Arlen 1973, 23-26; Haas 2010, 104-5). Following Hanrahan's interview with the Chicago Tribune, the Chicago Sun Times ran an article entitled "Bullet Holes Were Nail-Heads," reporting that many of the bullet holes alleged by Hanrahan in the photos were in fact nailheads (Haas 2010, 107). The New York Times echoed this story the next day. The New York Times ran a total of twenty-three articles in December related to the Hampton killing, and local coverage in Chicago was much more intense. When trials began for the surviving Panthers at Fred Hampton's apartment, in response to the sympathetic press coverage, defense attorneys broke with standard practice to "tell the press what happened" as part of a novel strategy to exploit public goodwill. The district attorney, Hanrahan, was furious with what he called an attempt to "try their case in the press" (Haas 2010, 103), and another cycle of coverage ensued.

To summarize the Hampton assasination, although it was a highly newsworthy event, much of the attention to the event was due to the way in which it drew other actors into the conflict and how those actors sought media attention in response to one another's media attention. Particularly in light of positive framings of the Panthers in more liberal news outlets, conservative news outlets gave a sympathetic outlet for Panthers' opponents, mostly Edward Hanrahan. These framings, such as the "nailheads" photos, were then contested by outlets that were more sympathetic to the Panthers (or perhaps simply more committed to objective reporting). This cycle of contestation continued to fan attention to the Hampton assassination long after the event itself was over. Because this type of framing contest is central to the expansion of the scope of conflict, both postive and negative representations of an SMO are likely to result from, and feed into, positive feedback (Gamson and Wolfsfeld 1993; Meyer and Staggenborg 1996, 1638, 1641).

As figure 8 (below) shows, attention to Hanrahan over this period becomes increasingly tied to the Panthers. Increasingly, when Hanrahan makes the news, he is mentioned alongside the Panthers. While this was in part due to the Panthers generating attention to Hanrahan, it is clear that Hanrahan was already a prominent news story before becoming intertwined with the Panthers. 
Figure 8. Attention to Edward Hanrahan and Black Panthers in the Chicago Tribune

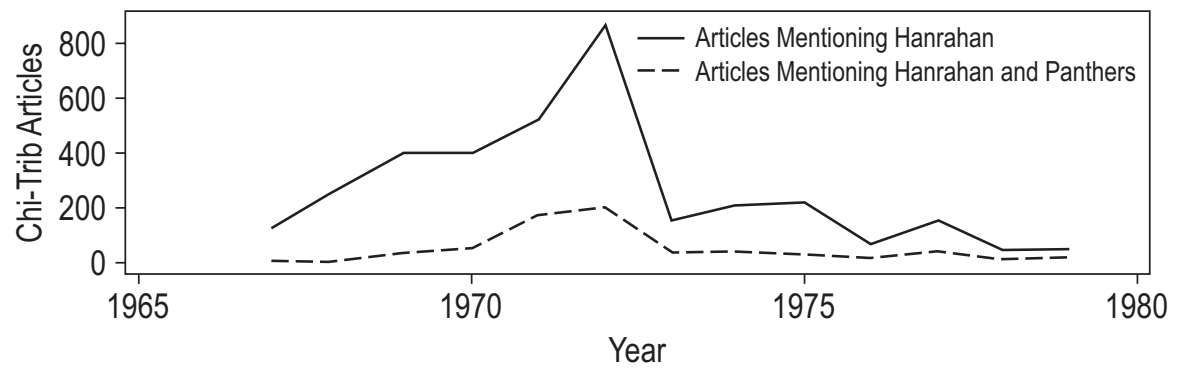

Percent of Hanrahan Articles Mentioning the Black Panthers

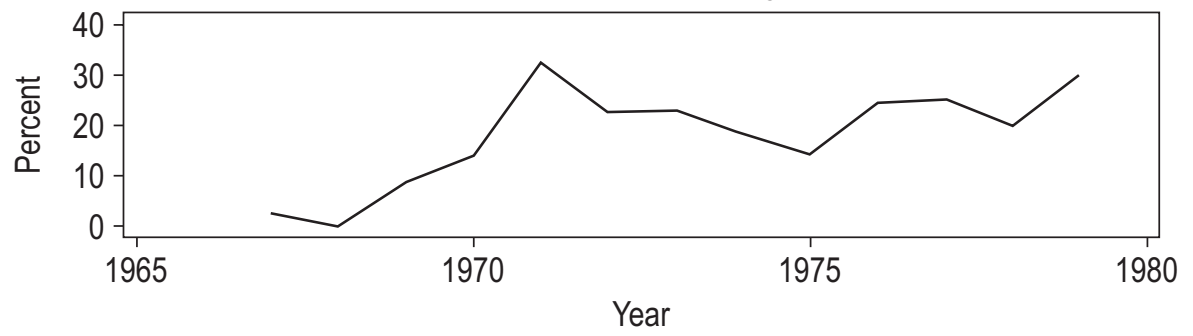

Note: The figure above displays the relationship between coverage of Edward Hanrahan and the Black Panthers in the Chicago Tribune. The first panel displays the number of articles that mention Hanrahan, and the number of articles that mention both Hanrahan and the Panthers. The second panel shows the percent of all Hanrahan articles that also mention the Panthers. The figure shows that Hanrahan's coverage becomes increasingly tied to the Panthers up until 1971, the year immediately following Fred Hampton's assassination, after which it levels off at about 20 percent. The increasing over time in the second panel is statistically significant $(p<.01)$. There are 3,432 articles mentioning Hanrahan and 635 articles mentioning both Hanrahan and the Panthers.

\section{Summary}

The bias model fails to explain the rise of the Panthers to the media spotlight. Rather, the Panthers' rise occurred through a set of interactive mechanisms, in which prior media attention was turned into future media attention. A dramatic new tactic of armed protest launched the Black Panthers into the national media spotlight, attracting more resources to the organization. These new resources in turn were leveraged for additional media attention. Throughout, increasing media attention went hand in hand with expansion of the scope of conflict and the Panthers becoming embedded in a news narrative.

The single case of the Black Panthers does not prove the theory of positive feedback. However, while the Panthers are a historically unique case, the structure and dynamics of their media attention are similar to many other cases. First, there are similar dynamics in the trajectories of other SMOs, with Students for a Democratic Society being the best documented (Gitlin 1980). Second, while the Panthers' media attention would be an outlier in any linear model, they are not an outlier from the power-law distribution of media attention to SMOs; thus, the Panthers' dominance of the media attention to the Black Power movement, while 
striking, is part of a general pattern of a handful of organizations capturing orders of magnitude more attention than typical organizations. Third, the mechanisms through which the positive feedback process for the Panthers occurred have been demonstrated in many other studies of SMOs and media attention.

\section{Conclusions}

"Bias models" of media attention argue, or assume implicitly, that characteristics of SMOs and their political environments are exogenous drivers of media attention. In this paper, I argued that media attention to some SMOs is best understood as a dynamic process where SMO characteristics and their political environments are both causes and consequences of media attention. Through interactions between both SMOs and the media, as well as between media outlets and journalists themselves, media attention to SMOs can unfold as a positive feedback process where past attention encourages future attention. Consistent with formal models of positive feedback, I showed that the distribution of media attention across US SMOs was power-law distributed in national print and television media. In a case study of the Black Panthers' media cascade, one of the largest and most dramatic in US history, I showed that media attention to the Panthers unfolded in a positive feedback process, through mechanisms identified in prior research.

The results support many central claims made by scholars of contentious politics and social theory: (1) timing and sequence matters, as Tilly puts it: "when things happen affect how they happen" (1984); (2) political action is underdetermined (Sewell 1996); (3) politics are path dependent (Lipset and Rokkan 1967, 53); (4) initial causes for the existence of an enduring social pattern may be different than the mechanisms that reproduce it (Stinchcombe 1968); (5) political change often occurs in dramatic punctuations, rather than gradual shifts (Baumgartner and Jones 2009).

Path dependence suggests that the determinants of media attention differ over the course of an SMO's career, and that media attention to SMOs and events may differ significantly. That is, while SMOs may become institutionalized in the news media through contentious events, they may continue to receive attention for reasons other than important events (Amenta et al. 2012; Gamson 2004). Studies that focus only on events may fail to capture all the political media attention to movements and movement actors, and mischaracterize their temporal dynamics.

The role of historical accidents in positive feedback processes suggests that at critical junctures historical change is, to some extent, "up for grabs," allowing key individuals and events to have enduring impacts upon history. The Black Panther Party in 1966, for instance, was composed of a handful of militants with few resources, facing high levels of repression, and operating in obscurity in all but their local Bay Area. By 1970, however, they had become the organizational voice of Black Power. It is tempting to look at such a large effect as over-determined, as if it had to occur. Positive feedback suggests, however, that with small differences in history the fate of the BPP—and the Black Power movement as a whole-may have been quite different. 


\section{Notes}

1. Cascades of attention go by many names, including "media storms," "media hypes," and "waves." I refer to them as "cascades" throughout, since that is the most prominent term in the literature.

2. More specifically, distributions with power-laws in the right tail.

3. Many analysts use logarithmic binning for log-log plots. These plots tend to be noisy in the tails and are potentially misleading (Newman 2005). I do not employ any binning procedure.

4. News outlets differ in the temporal patterns of attention to the Panthers (Davenport 2010). Concerned about the national representativeness of the papers in figure 5, I compared their coverage to coverage in television and other print outlets. Records of television news are spotty before August 1968, when the Vanderbilt News Archive began systematically archiving newscasts. The best efforts to reconstruct them suggest that early coverage on television was similar to that of newspapers (Rhodes 2007, 67-71 and 157). Tracking monthly coverage from August 1968 to 1977 shows that month-to-month correlations between the number of television newscasts on NBC, $\mathrm{ABC}$, and CBS with the number of articles in the New York Times, Chicago Tribune, and Los Angeles Times were high, respectively: .75, .77, and .71. Comparing two Black papers, the New York Amsterdam News and the Chicago Defender, with mainstream White newspapers in the same city, the New York Times and Chicago Tribune, respectively, the month-to-month article count correlations between the two pairs of papers are .78 for New York and .90 for Chicago. Although electronic versions of local Oakland papers are not available, work with these sources suggests that the Panthers received more attention in these sources than others (Davenport 2010; Rhodes 2007); therefore, the papers in my sample should be interpreted as representative only of the national news cascade.

5. The "Self-Defense" part of the name was later dropped. I use "Black Panthers," "Panthers," and BPP interchangeably throughout.

6. Pronounced "fry" (Bloom and Martin 2013, 132).

7. Huey Newton estimates that he was pulled over 40-50 times in the early days of the BPP (Newton and Blake 2009, 129-30); none of these stops were reported in the national media in the days before the Panthers became a national story.

\section{Supplementary Material}

Supplementary material is available at Social Forces online, http://sf.oxfordjournals. org/.

\section{About the Author}

Charles Seguin is a PhD candidate in sociology at the University of North Carolina. He studies politics, history, and culture using computational methods. His dissertation is on the meaning of lynching in America, 1880-1950.

\section{References}

Amenta, Edwin, Neal Caren, Sheera Joy Olasky, and James E. Stobaugh. 2009. "All the Movements Fit to Print: Who, What, When, Where, and Why SMO Families Appeared in the New York Times in the Twentieth Century." American Sociological Review 74(4):636-56. 
Amenta, Edwin, Beth Gharrity Gardner, Amber Celina Tierney, Anaid Yerena, and Thomas Alan Elliott. 2012. "A Story-Centered Approach to the Newspaper Coverage of High-Profile SMOs." Research in Social Movements, Conflicts, and Change 33:83-107.

Andrews, Kenneth T., and Neal Caren. 2010. "Making the News." American Sociological Review75(6):841-66. Arlen, Michael J. 1973. An American Verdict. Garden City, NY: Doubleday.

Arthur, Brian, Yu M. Ermoliev, and Yu M. Kaniovski. 1987. "Path-Dependent Processes and the Emergence of Macro-Structure." European Journal of Operational Research 30(3):294-303.

Atkinson, Mary Layton, John Lovett, and Frank R. Baumgartner. 2014. "Measuring the Media Agenda." Political Communication 31(2):355-80.

Austin, Curtis. 2006. Up against the Wall: Violence in the Making and Unmaking of the Black Panther Party. Fayetteville: University of Arkansas Press.

Bail, Christopher A. 2012. "The Fringe Effect Civil Society Organizations and the Evolution of Media Discourse about Islam since the September 11th Attacks." American Sociological Review 77(6):855-79.

Baumgartner, Frank R., and Bryan D. Jones. 2009. Agendas and Instability in American Politics. Chicago: University of Chicago Press.

Biggs, Michael. 2005. "Strikes as Forest Fires: Chicago and Paris in the Late Nineteenth Century." American Journal of Sociology 110(6):1684-714.

Bloom, Joshua, and Waldo Martin. 2013. Black against Empire: The History and Politics of the Black Panther Party. Berkeley: University of California Press.

Boydstun, Amber E. 2013. Making the News: Politics, the Media, and Agenda Setting. Chicago: University of Chicago Press.

Brüggemann, Michael, Sven Engesser, Florin Büchel, Edda Humprecht, and Laia Castro. 2014. "Hallin and Mancini Revisited: Four Empirical Types of Western Media Systems." Journal of Communication 64(6):1037-65.

Clauset, Aaron, Cosma Shalizi, and Mark Newman. 2009. "Power-Law Distributions in Empirical Data." SIAM Review 51(4):661-703.

Davenport, Christian. 2005. "Understanding Covert Repressive Action: The Case of the US Government against the Republic of New Africa." Journal of Conflict Resolution 49(1):120-40.

2010. Media Bias, Perspective, and State Repression: The Black Panther Party. Cambridge: Cambridge University Press.

Davies, James B., Susanna Sandström, Anthony B. Shorrocks, and Edward N. Wolff. 2009. The Level and Distribution of Global Household Wealth. National Bureau of Economic Research. http://www.nber.org/ papers/w15508.

Earl, Jennifer, Andrew Martin, John McCarthy, and Sarah A. Soule. 2004. “The Use of Newspaper Data in the Study of Collective Action." Annual Review of Sociology 30:65-80.

Earl, Jennifer, Sarah A. Soule, and John D. McCarthy. 2003. “Protest under Fire? Explaining the Policing of Protest." American Sociological Review 68(4):581-606.

Fishman, Mark. 1978. "Crime Waves as Ideology." Social Problems 25(5):531-43.

Galtung, Johan, and Mari Holmboe Ruge. 1965. "The Structure of Foreign News." Journal of Peace Research 2(1):64-91.

Gamson, William A. 1975. The Strategy of Social Protest. Homewood, IL: Dorsey Press. 2004. Protest in Time and Space: The Blackwell Companion to Social Movements. Malden, MA: Blackwell.

Gamson, William A., and Gadi Wolfsfeld. 1993. "Movements and Media as Interacting Systems." Annals of the American Academy of Political and Social Science 528:114-25.

Gerlach, Luther P., and Virginia Hine. 1970. People, Power, Change: Movements of Social Transformation. Indianapolis: Bobbs-Merrill.

Gitlin, Todd. 1980. The Whole World Is Watching: Mass Media in the Making \& Unmaking of the New Left. Berkeley: University of California Press. 
Gorman, Brandon, and Charles Seguin. Forthcoming. "Reporting the International System: Attention to Foreign Leaders in the US News Media, 1950-2008." Social Forces.

Haas, Jeffrey. 2010. The Assassination of Fred Hampton: How the FBI and the Chicago Police Murdered a Black Panther. Chicago: Chicago Review Press.

Hall, James, Ed. 1978. Policing the Crisis. London: Palgrave Macmillan.

Hilgartner, Stephen, and Charles Bosk. 1988. "The Rise and Fall of Social Problems: A Public Arenas Model." American Journal of Sociology 94(1):53-78.

Jeffries, Hasan Kwame. 2009. Bloody Lowndes: Civil Rights and Black Power in Alabama's Black Belt. New York: New York University Press.

Joseph, Peniel. 2010. Dark Days, Bright Nights: From Black Power to Barack Obama. New York: BasicCivitas Books.

Koopmans, Ruud. 2004. "Movements and Media: Selection Processes and Evolutionary Dynamics in the Public Sphere." Theory and Society 33(3-4):367-91.

Koopmans, Ruud, and Susan Olzak. 2004. "Discursive Opportunities and the Evolution of Right-Wing Violence in Germany." American Journal of Sociology 110(1):198-230.

Koopmans, Ruud, and Rens Vliegenthart. 2011. "Media Attention as the Outcome of a Diffusion ProcessA Theoretical Framework and Cross-National Evidence on Earthquake Coverage." European Sociological Review 27(5):636-53.

Lipset, Seymour Martin, and Stein Rokkan. 1967. "Cleaveage Structures, Party Systems, and Voter Alignments: An Introduction." In Party Systems and Voter Alignments: Cross-National Perspectives, edited by S. Rokkan and S. M. Lipset, 1-64. New York: Free Press.

McCarthy, John, Clark McPhail, and Jackie Smith. 1996. "Images of Protest: Dimensions of Selection Bias in Media Coverage of Washington Demonstrations, 1982 and 1991." American Sociological Review 61(3):478-99.

McCarthy, John, and Mayer N. Zald. 1977. "Resource Mobilization and Social Movements: A Partial Theory." American Journal of Sociology 82(6):1212-41.

Meyer, David S., and Suzanne Staggenborg. 1996. "Movements, Countermovements, and the Structure of Political Opportunity." American Journal of Sociology 101:1628-60.

Myers, Daniel, and Beth Schaefer Caniglia. 2004. "All the Rioting That's Fit to Print: Selection Effects in National Newspaper Coverage of Civil Disorders, 1968-1969." American Sociological Review69(4):519-43.

Newman, Mark. 1996. "Self-Organized Criticality, Evolution, and the Fossil Extinction Record." Proceedings: Biological Sciences 263(1376):1605-10.

2005. "Power Laws, Pareto Distributions, and Zipf's Law." Contemporary Physics 46(5):323-51.

Newton, Huey P., and J. Herman Blake. 2009. Revolutionary Suicide. New York: Penguin Books.

Ogbar, Jeffrey, and Ogbonna Green. 2004. Black Power: Radical Politics and African American Identity. Baltimore, MD: Johns Hopkins University Press.

Oliver, Pamela, and Daniel Myers. 1999. "How Events Enter the Public Sphere: Conflict, Location, and Sponsorship in Local Newspaper Coverage of Public Events." American Journal of Sociology 105(1):38-87.

2003. "The Coevolution of Social Movements." Mobilization 8(1):1-24.

Rhodes, Jane. 2007. Framing the Black Panthers: The Spectacular Rise of a Black Power Icon. New York: New Press.

Seale, Bobby. 1991. Seize the Time: The Story of the Black Panther Party and Huey P. Newton. Baltimore, MD: Black Classic Press.

Sewell, William H. 1996. "Three Temporalities: Toward a Sociology of the Event." In The Historic Turn in the Human Sciences, edited by T. J. McDonald. Ann Arbor: University of Michigan Press.

Simon, Herbert H. A. 1955. "On a Class of Skew Distribution Functions." Biometrika 42(3-4):425-40.

Singh, Nikhil Pal. 1998. "The Black Panthers and the 'Undeveloped Country' of the Left." In The Black Panther Party Reconsidered, edited by C. E. Jones, 57-107. Baltimore, MD: Black Classic Press. 
Snow, David A., Rens Vliegenthart, and Catherine Corrigall-Brown. 2007. "Framing the French Riots: A Comparative Study of Frame Variation." Social Forces 86(2):385-415.

Sobieraj, Sarah. 2011. Soundbitten: The Perils of Media-Centered Political Activism. New York: New York University Press.

Stinchcombe, Arthur L. 1968. Constructing Social Theories. New York: Harcourt, Brace \& World.

Tilly, Charles. 1984. Big Structures, Large Processes, Huge Comparisons. New York: Russell Sage Foundation. Tyson, Timothy B. 1999. Radio Free Dixie: Robert F. Williams \& the Roots of Black Power. Chapel Hill: University of North Carolina Press.

Van de Rijt, Arnout, Eran Shor, Charles Ward, and Steven Skiena. 2013. "Only 15 Minutes? The Social Stratification of Fame in Printed Media." American Sociological Review 78(2):266-89.

Vliegenthart, Rens, Dirk Oegema, and Bert Klandermans. 2005. "Media Coverage and Organizational Support in the Dutch Environmental Movement." Mobilization: An International Journal 10(3):365-81.

Walgrave, Stefaan, and Rens Vliegenthart. 2010. "Why Are Policy Agendas Punctuated? Friction and Cascading in Parliament and Mass Media in Belgium." Journal of European Public Policy 17(8):1147-70.

Wendt, Simon. 2007. The Spirit and the Shotgun: Armed Resistance and the Struggle for Civil Rights. Gainesville: University Press of Florida. 